\title{
Formulation and In-Vitro Release Pattern Study of Gliclazide Matrix Tablet
}

\author{
Tanbir Ahammad1, Marium Begum², A. F. M. Towheedur Rahman3, Moynul Hasan4, \\ Saikat Ranjan Paul5, Shaila Eamen6, Md. Iftekhar Hussain², Md. Hazrat Ali'7, \\ Md. Ashraful Islam ${ }^{8}$, Mohammad Mizanur Rahman², Mamunur Rashid ${ }^{\text {** }}$ \\ ${ }^{1}$ Department of Pharmacy, BRAC University, Dhaka, Bangladesh \\ ${ }^{2}$ Department of Pharmacy, Primeasia University, Dhaka, Bangladesh \\ ${ }^{3}$ Department of Pharmaceutical Sciences, North South University, Dhaka, Bangladesh \\ ${ }^{4}$ Department of Pharmacy, Dhaka International University, Dhaka, Bangladesh \\ ${ }^{5}$ Department of Pharmacy, Southeast University, Dhaka, Bangladesh \\ ${ }^{6}$ Department of Pharmacy, Jahangirnagar University, Dhaka, Bangladesh \\ ${ }^{7}$ Department of Pharmacy, International Islamic University of Chittagong, Chittagong, Bangladesh \\ ${ }^{8}$ Department of Biomedical Imaging, Faculty of Bioscience, Abo Akademi University, Turku, Finland \\ ${ }^{9}$ Department of Pharmacy, University of Rajshshi, Rajshahi, Bangladesh \\ Email: ${ }^{*}$ mamun69jp@yahoo.com
}

Received 28 December 2014; accepted 3 March 2015; published 9 March 2015

Copyright @ 2015 by authors and Scientific Research Publishing Inc.

This work is licensed under the Creative Commons Attribution International License (CC BY).

http://creativecommons.org/licenses/by/4.0/

c) (i) Open Access

\begin{abstract}
In current decade, pharmaceutical industries of Bangladesh are giving much emphasize on the formulation of time release preparation to treat various chronic diseases in order to decrease the frequency of administration and to improve patient compliance. Objectives: The objective of this investigation is to design and evaluate sustained release matrix tablet of Gliclazide by direct compression method employing polymers of hydroxypropylmethyl cellulose (HPMC) derivatives (K15M CR and K4M CR) and to select the optimized formulations and compression process by performing a comparative release kinetic study with a reference product, Diamicron MR (one of the worldwide brand of Gliclazide sustain released tablet manufactured by Servier one of the French pharmaceutical company) tablet. Methods: Release kinetics of Gliclazide matrix tablets were determined using USP paddle method at Phosphate buffer (pH 7.4). The release mechanism was explored and explained with zero order, first order, Higuchi and Korsmeyer model. Result: It is found that formulation with lower polymeric concentration follows Higuchi release kinetics and that the formulation with higher concentration best fits with zero order release kinetics. Among the formulations, F1 and F6 show almost similar dissolution profile with Diamicron MR Tablet, which can be suitable candidates for further in-vivo bioequivalence study. Conclusion: Findings of
\end{abstract}

${ }^{*}$ Corresponding author.

How to cite this paper: Ahammad, T., Begum, M., Rahman, A.F.M.T., Hasan, M., Paul, S.R., Eamen, S., Hussain, M.I., Ali, M.H., Islam, M.A., Rahman, M.M. and Rashid, M. (2015) Formulation and In-Vitro Release Pattern Study of Gliclazide Matrix Tablet. Pharmacology \& Pharmacy, 6, 125-131. http://dx.doi.org/10.4236/pp.2015.63015 
this investigation suggest that F1 and F6 formulations are potential candidates for further bioequivalence study among other formulations.

\title{
Keywords
}

\author{
Gliclazide, Sustained Release, Methocel K15M CR, Methocel K4M CR, In-Vitro Bioequivalence
}

\section{Introduction}

Matrix systems appear to be a very attractive approach from the economic as well as from the process development and scale-up points of view in modified-release system [1]. Methocel (HPMC) is used frequently as a rate-controlling polymer in matrix tablets and offers some advantages of being non-toxic and relatively inexpensive; it can be compressed directly into matrix and is available in different chemical substitution, hydration rates and viscosity grades [2]. In general, most of the sustain release matrix tablet manufactured by wet granulation process which is very tedious process and required organic granulation solvent because aqueous solvent make the process more tedious. But use of direct compression technique by using suitable excipients can give desired pharmaceutical and pharmacokinetic properties [3]. In the present study, direct compression method is used to produce matrix tablets.

Chemically Gliclazide is 1-(3-azabicyclo [3, 3, 0]oct-3-yl)-3-p-tolylsulphonylurea (Figure 1) which is a secondgeneration sulfonylurea, oral hypoglycemic drug and widely used in the treatment of non-insulin-dependent diabetes mellitus (NIDDM). However, the usage of the common formulation of gliclazide can be limited by some kinds of reasons, such as patient's age and renal impairment etc. [4].

Currently, both conventional and modified release preparation are available. But most of them are failed to give reproducible and desirable drug release profile and there is no evidence of bioavailability and bioequivalence study of such products in Bangladesh. So, a lot of researches are carried out to prepare modified release Gliclazide tablets with pharmacokinetic characteristics suited to the circadian glycemic profile of type II diabetes. This approach will minimize the complications associated with diabetes mellitus [4]. The development of a sustain release dosage form of Gliclazide will reduce the total requirement of API (In conventional tablet 80 $\mathrm{mg}$ per day is recommended where $30 \mathrm{mg} /$ day in sustain release tablet are recommended [5] hence reduce the side effect and chance of hypoglycemic effect. Same time it reduces the price of drug and makes the drug more affordable to the patients. For those reasons, an attempt has been taken to develop a Giclazide sustained release matrix tablets and their dissolution profiles were compared by determining similarity and difference factor that are introduced by Moor and Flanner, 1996 [6]. This comparison will help the health professionals to find the best alternative. From the point of view of formulation scientist and commercial personnel, it is excellent tool to select one or two suitable formulation(s) for in-vitro bioequivalence study which will be more rational and cost effective instead of going for several formulations on the basis of random selection.

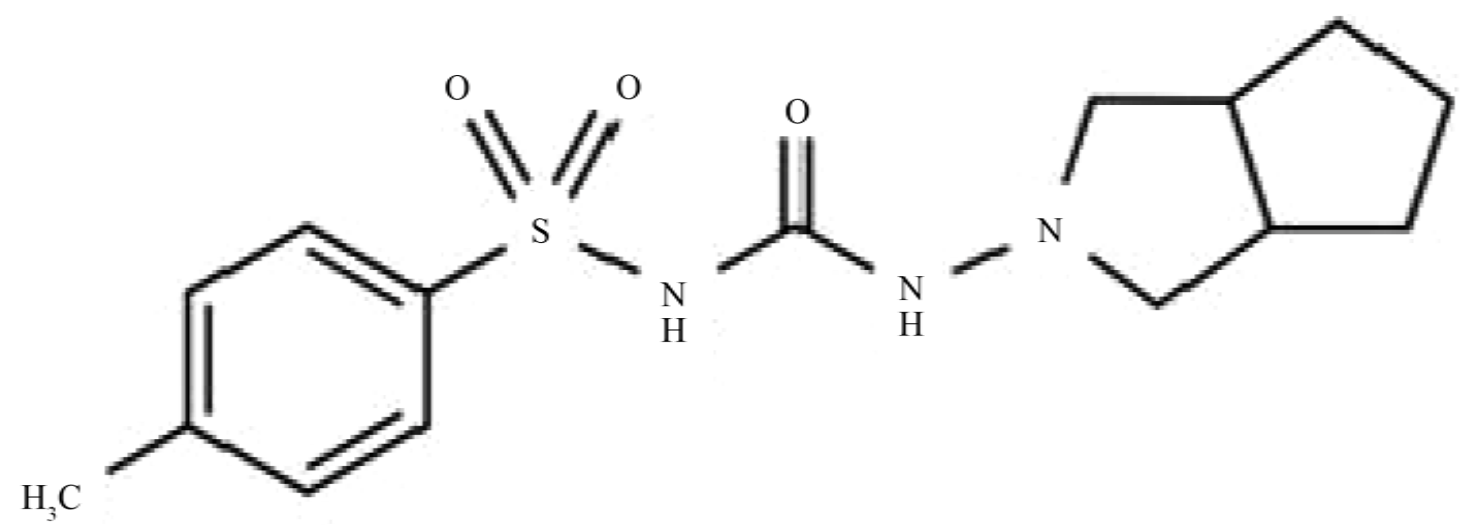

Figure 1. Chemical structure of Gliclazide. 


\section{Materials and Methods}

\subsection{Table Preparation by Direct Compression Technique}

Individual ingredient was taken according to Table 1 and was sieved through 30 mesh sieve. At first, Gliclazide and polymer (Methocel K15M CR or K4M CR) were mixed uniformly. Then lactose was added with this mixture and finally the powder mix was lubricated with magnesium stearate. Tablets were made by a compression machine (Erweka, TR 16, Germany) using a $5 \times 10 \mathrm{~mm}$ caplet shaped punch and die set. Formulation code F1, F2, F3 represents the gliclazide matrix tablet prepared with Methocel K15M CR and Formulation code F4, F5, F6 represents the gliclazide matrix tablet prepared with Methocel K4M CR.

\subsection{Study of Physical Properties of the Formulated Tablets}

The weight variation was determined by taking 10 tablets using an electronic balance (AY120, Shimadzu, Japan). Friability was determined by testing 10 tablets in a friability tester (FTA-20, Campbell Electronics) for 4 minutes at $25 \mathrm{rpm}$. Tablet thickness, diameter and hardness were determined for 6 tablets using a Sotax HT10.

\subsection{Dissolution Study of the Matrix Tablet}

All dissolution studies were carried out for extended release Gliclazide formulations according to USP XII. Phosphate buffer at $\mathrm{pH} 7.4$ was used as dissolution medium. The amount of Gliclazide was determined by employing UV spectrophotometer to measure the absorbance at the wavelength of maximum $226 \mathrm{~nm}$ and $290 \mathrm{~nm}$. For this purpose absorbance of Standard solution against standard blank solution ( $0.6 \mathrm{ml}$ methanol was diluted to $100 \mathrm{ml}$ by Phosphate buffer ( $\mathrm{pH}$ 7.4) and absorbance of sample solution against phosphate buffer (at $\mathrm{pH}$ 7.4) using $1 \mathrm{~cm}$ cell were measured. Differences between these two absorbances (at 226 and $290 \mathrm{~nm}$ ) were calculated.

\section{Result and Discussion}

All of the studied physical properties were within the acceptable range with narrow variation and complied with the pharmacopoeial specifications for hardness, friability and weight variation. Range of hardness was 9.8 to $10.5 \mathrm{Kpa}$, friability was below $1.0 \%$ and rage was $0.34 \%$ to $0.40 \%$ and weight variation was $1.4 \%$ to $1.8 \%$ which is below $5 \%$.

\subsection{Effect of Methocel K15M CR on Release Pattern of Gliclazide from Matrix Tablet}

Figure 2 is displaying the zero order release of Gliclazide from Methocel K15M CR (A) and Methocel K4M CR (B) and Figure 3 is displaying Higuchi release of Gliclazide from Methocel K15M CR (A) and Methocel K4M CR (B).

The release profile of Gliclazide was monitored up to 10 hours. Figure 2(a) and Figure 3(a) represent the zero order and Higuchi release profile of Gliclazide matrix tablet compressed by direct compression. The total \% of Gliclazide release from the formulation F1, F2 and F3 were 64.566\%, 56.83\% and 55.293\% respectively. It has been observed that the drug release was extended with the increase of polymer $\%$ and with the decrease of lactose $\%$ which is due to a decrease in the total porosity i.e. release is extended to long period. Lactose causes a

Table 1. Composition of Gliclazide matrix tablets (mg/tablet; per tablet $180 \mathrm{mg}$ ).

\begin{tabular}{ccccccc}
\hline Formulation & Gliclazide & \% of Polymer & K15M CR & K4M CR & Lactose & Mg-Stearate \\
\hline F1 & 30 & 20 & 36 & - & 113.1 & 0.9 \\
F2 & 30 & 25 & 45 & - & 104.1 & 0.9 \\
F3 & 30 & 30 & 54 & - & 95.1 & 0.9 \\
F4 & 30 & 20 & - & 36 & 113.1 & 0.9 \\
F5 & 30 & 25 & - & 45 & 104.1 & 0.9 \\
F6 & 30 & 30 & - & 54 & 95.1 & 0.9 \\
\hline
\end{tabular}




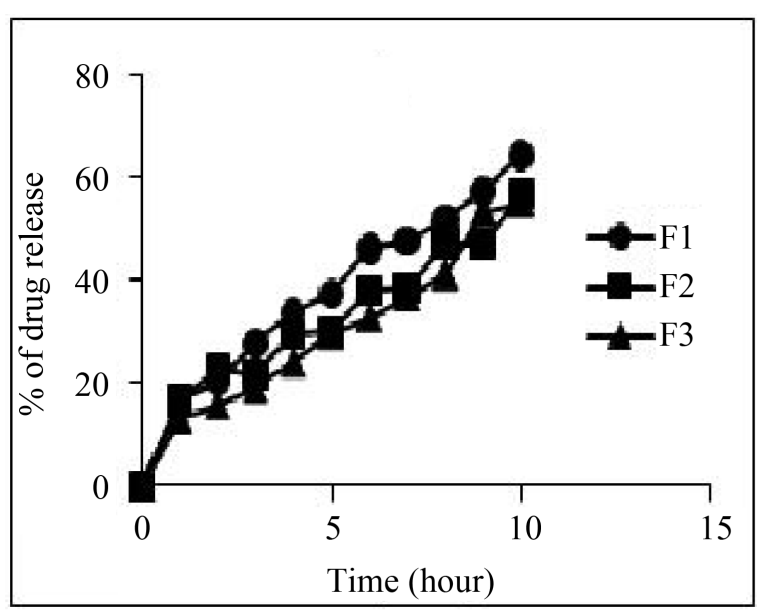

(a)

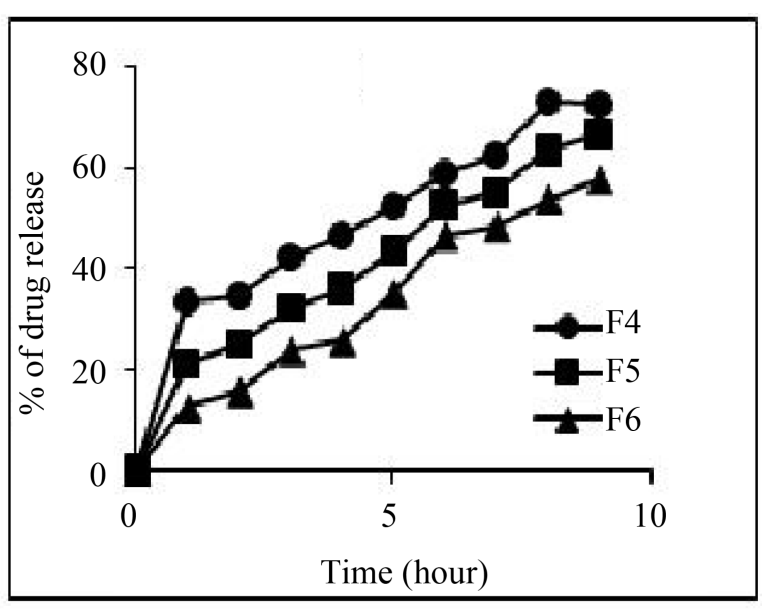

(b)

Figure 2. Zero order release of Gliclazide from Methocel K15M CR (a) and Methocel K4M CR (b).

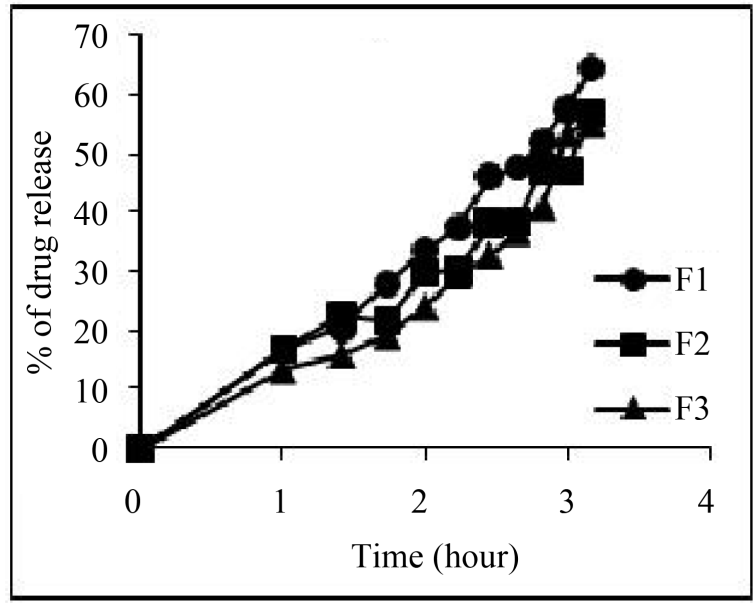

(a)

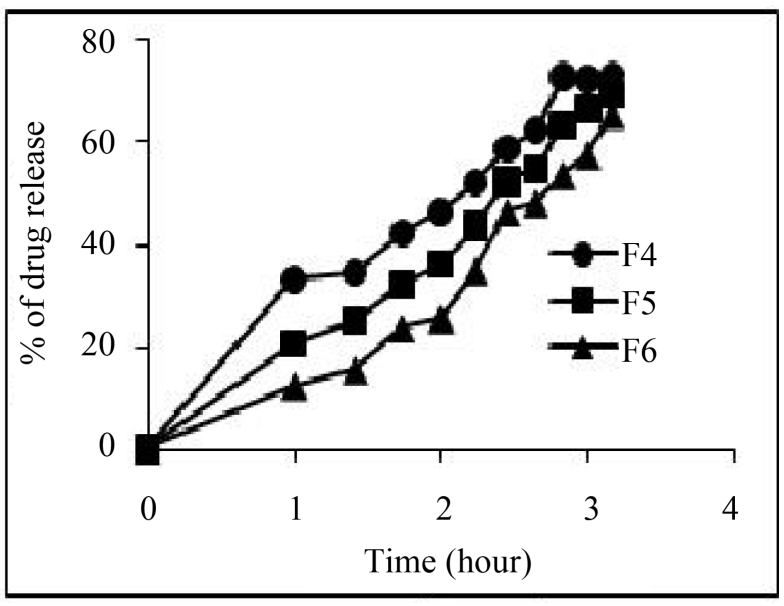

(b)

Figure 3. Higuchi release of Gliclazide from Methocel K15M CR (a) and Methocel K4M CR (b).

decreased tortuosity of the path of the drug due to its preferential solubility than Methocel K15 M CR, by its swelling effect; additionally weakened the integrity of the matrix [7]. The highest percent of drug release within 10 hours is obtained from formulation F1 where polymer content is $20 \%$ of total tablet weight. But in Formulation F3, the polymer content is $30 \%$ of total tablet weight and lactose content is $52.83 \%$, the release of drug is controlled with $55.29 \%$ within 10 hours.

The kinetics data are presented in Table 2 and it has been seen that all these formulations of this class show good linearity for Korsmeyer plot ( $\mathrm{r}^{2}: 0.973$ to 0.924$)$ and follow Anomalous or non-Fickian transport (n: $>0.45$ and $<0.89$ ). From the table, it has been seen that all these formulations of this class follows zero order, first order and Higuchi release model. Formulation F1 best fits with first order release model followed by Higuchi and zero order where F2 best fit for Higuchi and F3 for zero order.

\subsection{Effect of Methocel K4M CR on Release Pattern of Gliclazide Matrix Tablet}

The release profile of Gliclazide from formulation F4, F5 and F6 were monitored up to 10 hours. Figure 2(b) and Figure 3(b) represent the zero order and Higuchi release profile of Gliclazide matrix tablet containing polymer Methocel K4M CR. The total \% of Gliclazide release from the formulation F4, F5 and F6 were 73.076\%, $69.259 \%$, and $65.45 \%$ respectively.

The kinetics data are presented in Table 3 and it has been seen that all the formulations of this class show 
Table 2. Kinetic parameters of Gliclazide matrix tablets containing Methocel K15M CR.

\begin{tabular}{|c|c|c|c|c|c|c|c|c|c|}
\hline \multirow{2}{*}{$\begin{array}{l}\text { Formulation } \\
\text { code }\end{array}$} & \multirow{2}{*}{$\begin{array}{l}\text { Gliclazide } \\
\text { release (\%) } \\
\text { after } 10 \text { hrs }\end{array}$} & \multicolumn{2}{|c|}{ Zero order } & \multicolumn{2}{|c|}{ First order } & \multicolumn{2}{|c|}{ Higuchi } & \multicolumn{2}{|c|}{ Korsmeyer } \\
\hline & & $r^{2}$ & $\mathrm{~K}_{0}$ & $r^{2}$ & $\mathrm{~K}_{1}$ & $r^{2}$ & $\mathrm{~K}_{\mathrm{H}}$ & $r^{2}$ & $\mathrm{n}$ \\
\hline $\mathrm{F} 1$ & 64.566 & 0.969 & 5.755 & 0.984 & -0.040 & 0.976 & 20.06 & 0.924 & 0.517 \\
\hline F2 & 56.83 & 0.945 & 4.751 & 0.953 & -0.030 & 0.953 & 16.58 & 0.978 & 0.603 \\
\hline F3 & 55.293 & 0.974 & 5.051 & 0.953 & -0.032 & 0.922 & 17.07 & 0.938 & 0.645 \\
\hline
\end{tabular}

Table 3. Kinetic parameters of Gliclazide matrix tablets containing Methocel K4M CR.

\begin{tabular}{|c|c|c|c|c|c|c|c|c|c|}
\hline \multirow{2}{*}{$\begin{array}{l}\text { Formulation } \\
\text { code }\end{array}$} & \multirow{2}{*}{$\begin{array}{l}\text { Gliclazide } \\
\text { release (\%) } \\
\text { after } 10 \text { hrs }\end{array}$} & \multicolumn{2}{|c|}{ Zero order } & \multicolumn{2}{|c|}{ First order } & \multicolumn{2}{|c|}{ Higuchi } & \multicolumn{2}{|c|}{ Korsmeyer } \\
\hline & & $r^{2}$ & $\mathrm{~K}_{0}$ & $r^{2}$ & $\mathrm{~K}_{1}$ & $r^{2}$ & $\mathrm{~K}_{\mathrm{H}}$ & $\mathrm{r}^{2}$ & $\mathrm{n}$ \\
\hline F4 & 73.07 & 0.885 & 6.266 & 0.958 & -0.054 & 0.978 & 22.89 & 0.936 & 0.395 \\
\hline F5 & 69.26 & 0.961 & 6.414 & 0.988 & -0.049 & 0.979 & 22.50 & 0.970 & 0.565 \\
\hline F6 & 65.44 & 0.985 & 6.287 & 0.980 & -0.043 & 0.936 & 21.31 & 0.966 & 0.769 \\
\hline
\end{tabular}

good linearity for Korsmeyer plot $\left(\mathrm{r}^{2}: 0.991\right.$ to 0.936$)$ where Formulation F4 follow Fickian (case I) diffusion (n: $0.395<0.45$ ) and others follow Anomalous or non-Fickian transport $(\mathrm{n}>0.45$ but $<0.89$ ).

From Table 3, it has also been seen that formulation F5 best fits with first order release model follow by Higuchi and zero order where Formulation F4 best fit for Higuchi and F6 for zero order. Same trend was observed in formulations F1 to F3 where release kinetics shift from first order to zero order kinetics with the increase the \% of polymer (20\% to $30 \%)$.

\subsection{Comparative Release Pattern Study between Diamicron MR Tablet and the Proposed Sustained Release Formulations}

Figure 4 is showing Comparative in vitro Gliclazide release profile of Formulation F1 (A) \& F6 (B) against Diamicron MR Tablet. The release rate of the proposed formulations were compared with the innovator's drug Diamicron MR Tablet in terms of Difference Factor $\left(f_{1}\right)$ and Similarity Factor $\left(f_{2}\right)$ [6]. For this purpose Diamicron MR (worldwide brand) of Servier was collected from local market and the dissolution of this product was studied for 10 hours in the same condition of the test sample. Similarity Factor $\left(f_{2}\right)$ and Difference Factor $\left(f_{1}\right)$ were determined by using the equation developed by Moor and Flanner (Equations (1) and (2)) and results are summarized in Table 4.

$$
\begin{gathered}
f_{2}=50 \log \left[\left\{1+1 / \mathrm{n}(\mathrm{Rt}-\mathrm{Tt})^{2}\right\}^{-0.5} \times 100\right] \\
f_{1}=[\{|\mathrm{Rt}-\mathrm{Tt}| / \mathrm{Rt}\} \times 100]
\end{gathered}
$$

where Rt and Tt are the percent drug dissolved at each time point for the reference and test products, respective$\mathrm{ly} ; \mathrm{n}$ is the number of dissolution sample times and $\mathrm{t}$ is the time points for collecting dissolution samples.

From the above study, it is seen that among the proposed formulations F1 and F6 are more likely to meet the specification with Diamicron MR in terms of Difference Factor $\left(f_{1}\right)$ and Similarity Factor $\left(f_{2}\right)$ and their release profile with Diamicron MR (Figure 4) are very identical. But others formulations don't showed desired dissolution pattern. Some are showing faster dissolution than Diamicron MR where others showing slower dissolution.

\section{Conclusion}

In the present study, Gliclazide matrix tablets have been prepared by employing polymers K15M CR and K4M CR with good tabletting properties like weight variation, thickness, diameter, hardness and friability (Table 5). Among the formulations, formulations F1 (containing 36 mg K15M CR) and F6 (containing 54 mg K15M CR) better meet the specification in terms of Difference Factor $\left(f_{1}\right)$ and Similarity Factor $\left(f_{2}\right)$ and exhibit similar release profile with Diamicron MR tablet. Both the Formulations F1 \& F6 follow Anomalous or non-Fickian 
Table 4. Summary of $f_{1}$ and $f_{2}$ test.

\begin{tabular}{ccc}
\hline Formulation & Difference factor, $\left(f_{1}\right)(0$ to 15$)$ & Similarity factor, $\left(f_{2}\right)(50$ to 100$)$ \\
\hline F1 & 5.6 & 72.3 \\
F2 & 17.9 & 54.2 \\
F3 & 21.6 & 50.7 \\
F4 & 34.6 & 41.3 \\
F5 & 14.2 & 59.0 \\
F6 & 7.3 & 70.6 \\
\hline
\end{tabular}

Table 5. Physical properties of the designed Gliclazide matrix tablets.

\begin{tabular}{cccccc}
\hline Formulation & Hardness (Kpa) & Thickness $(\mathrm{mm})$ & Diameter $(\mathrm{mm})$ & Friability (\%) & Weight Variation \\
\hline F1 & $09.9 \pm 0.05$ & 3.31 & 10.02 & 0.35 & \pm 1.8 \\
F2 & $10.1 \pm 0.08$ & 3.32 & 10.01 & 0.37 & \pm 1.4 \\
F3 & $10.5 \pm 0.10$ & 3.30 & 10.00 & 0.34 & \pm 1.6 \\
F4 & $10.3 \pm 0.50$ & 3.33 & 10.00 & 0.38 & \pm 1.6 \\
F5 & $10.3 \pm 0.50$ & 3.34 & 10.01 & 0.38 & \pm 1.4 \\
F6 & $09.8 \pm 0.10$ & 3.33 & 09.99 & 0.40 & \pm 1.7 \\
\hline
\end{tabular}

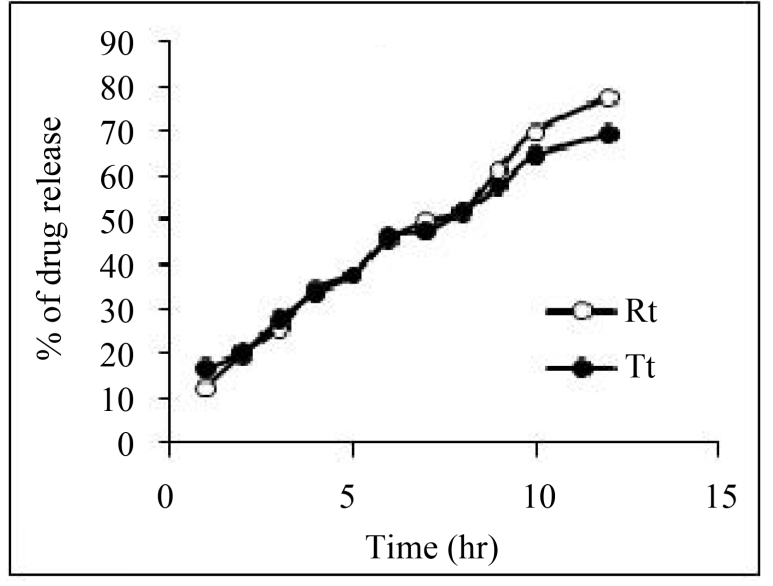

(a)

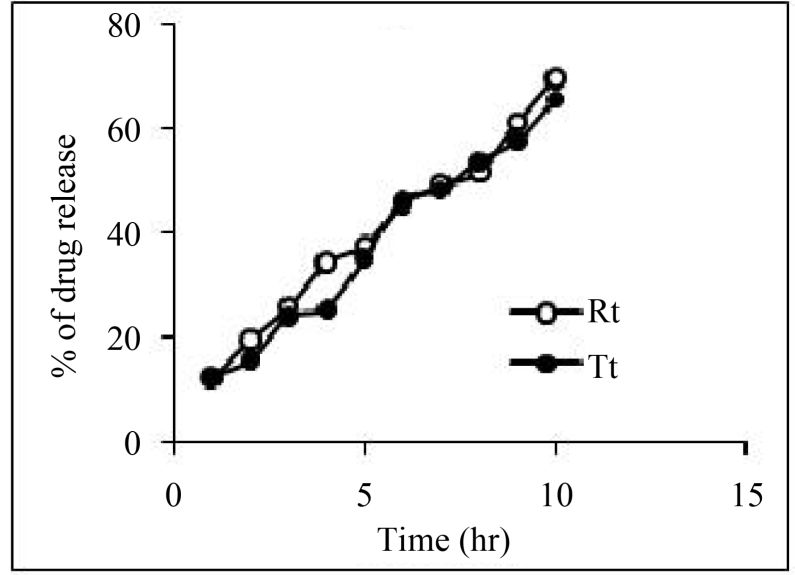

(b)

Figure 4. Comparative in vitro Gliclazide release profile of Formulations F1 (a) \& F6 (b) against Diamicron MRTablet [Rt and Tt indicates the reference tablet and test tablet respectively].

transport. Formulation F1 best fits with first order release model indicating concentration dependent drug release where as Formulation F6 best fits with zero order release model indicating that the drug is released from the matrix tablet by both diffusion and erosion. For the further bioequivalence study, these two (F1 \& F6) will be more prominent candidates than other formulations.

\section{Acknowledgements}

Authors are thankful to SQUARE Pharmaceuticals Ltd., Bangladesh for proving manufacturing facilities.

\section{Conflict of Interest}

The authors declare that they have no conflict of interest to disclose. 


\section{References}

[1] Rekhi, G.S., Nellore, R.V. and Hussain, A.S. (1999) Identification of Critical Formulation and Processing Variables form Extended-Release (ER) Matrix Tablet. Journal of Controlled Release, 59, 327-342. http://dx.doi.org/10.1016/S0168-3659(99)00004-8

[2] Perez-Marcos, B., Ford, J.L. and Amstrong, D.J. (1994) Release of Propranolol Hydrochloride from Matrix Tablets Containing Hydroxyl Propyl Methyl Cellulose K4M and Carbopol 974. International Journal of Pharmaceutics, 111, 251-259. http://dx.doi.org/10.1016/0378-5173(94)90348-4

[3] Ahammad, T., Hasan, M., Ahamed, I. and Islam, M.A., (2011) Effect of Granulation Technique and Drug-Polymer Ratio on Release Kinetics of Gliclizade from Methocel K15M CR Matrix Tablet. International Journal of Pharmaceutical Sciences and Research, 2, 1063-1068.

[4] British Pharmacopoeia (2009) The Stationery Office, London, Vol. I, 2761.

[5] McGavin, J.K., Perry, C.M. and Goa, K.L. (2002) Gliclazide Modified Release. Drugs, 62, 1357-1364. http://dx.doi.org/10.2165/00003495-200262090-00010

[6] Moore, J.W. and Flanner, H.H. (1996) Mathematical Comparison of Curves with an Emphasis on in Vitro Dissolution Profiles. Pharmaceutical Technology, 20, 64-74.

[7] Ju, R.T.C., Nixon, P.R., Patel, M.V. and Tong, D.M. (1995) A Mechanistic Model for Drug Release from Hydrophilic Matrixes Based on the Structure of Swollen Matrices. Proceedings International Symposium on Control. Rel. Bioact. Mater, 22, 59-60. 